*Doutor em Administração da Saúde, vinculado ao Centro de Administração e Políticas Públicas (CAPP), Lisboa, Portugal.E-mail: anunes@iscsp.ulisboa.pt

**Licenciada em Direito, jurista no Ministério da Saúde, vinculada à Faculdade de Direito da Universidade de Lisboa.E-mail: rosa.raposeiro@ms.gov.pt.

\section{Saúde em Portugal: Análise do Direito REgULATÓRIO}

\author{
Health in Portugal: Analysis of the Regulatory \\ RigHT
}

\author{
Alexandre Morais Nunes* \\ Rosa Raposeiro**
}

Como citar: NUNES, Alexandre Morais; RAPOSEIRO, Rosa. Saúde em Portugal: Análise do direito regulatório. Revista do Direito Público, Londrina, v. 16, n. 1, p. 85-96, abr. 2021. DOI: 10.5433/24157-108104-1.2021v16n1p. 85. ISSN: 1980-511X

Resumo: O Direito Regulatório representa a junção das regras de direito público, constitucional, econômico e administrativo, que orientam as agências de regulação. A regulação no sector da saúde em Portugal é realizada através da Entidade Reguladora da Saúde num sistema de saúde constituído por prestadores públicos e privados. O presente artigo, por meio de uma revisão da literatura e da legislação publicada pretende dar a conhecer o enquadramento legal da regulação da saúde em Portugal, considerando as várias revisões constitucionais e o desenvolvimento do Serviço Nacional de Saúde (SNS).

Palavras-chave: Direito à saúde. Direito regulatório. Regulação da saúde. Serviço Nacional de Saúde.

Abstract: Regulatory Law represents the combination of public, constitutional, economic, and administrative law, which guide regulatory agencies. Regulation in the health sector in Portugal is carried out through the Health Regulatory Entity in a health system made up of public and private providers. This article, by means of a review of the literature and public legislation, intends to make known the legal framework of health regulation in Portugal, considering the various constitutional revisions and the development of the NHS.

Keywords: Right to health. Regulatory Law. Health regulation. National Health Service. Portugal. 


\section{INTRODUÇÃO}

A Constituição da República Portuguesa de 1976 baseia-se num modelo de Estado Social que defende um conjunto de valores de liberdade, direitos fundamentais e direitos sociais (LEI n. ${ }^{\circ} 1 / 2005$ - última revisão).

$\mathrm{O}$ direito à saúde e o dever de a defender e promover são princípios constitucionais definidos no artigo $64^{\circ}$ da Constituição e é consagrado como a base do sistema de saúde (NOVAIS, 2010).

O sistema de saúde português é constituído por um grande prestador público, o Serviço Nacional de Saúde (SNS) e por um conjunto de prestadores privados (empresas privadas) e social (Instituições de solidariedade social e santa casa da misericórdia) (FERNANDES, 2015).

O SNS é financiado pelo Estado e garante uma cobertura universal de assistência à saúde (para todos os cidadãos), geral (em todas as necessidades) e com tendencial gratuidade (cobradas taxas pouco significativas para moderar o acesso. Porém existem pacientes isentos, entre outras razões por condições de saúde ou por insuficiência econômica). Por revestir uma imposição constitucional, o Serviço Nacional de Saúde tem uma vitalidade, durabilidade, independência e subsistência que vai muito além da vontade política do Governo (NOVAIS, 2010).

A atividade privada na Saúde existe em Portugal e tem crescido desde a publicação da Lei de Bases da Saúde em 1990 que veio definir a importância deste sector na consecução dos seus objetivos, complementando o Serviço Nacional de Saúde. A mesma lei enquadrou também a importância das instituições particulares de solidariedade social com objectivos específicos de saúde envolvidos em uma ação comum a favor da saúde coletiva, de acordo com a Lei n. ${ }^{\circ}$ 48/90, de 24 de agosto (PORTUGAL, 1990).

A regulação ganha enorme importância pelo fato de se concentrar no monitoramento de uma entidade pública em uma determinada atividade (NOLL, 1985) por meio da intervenção independente de uma entidade reguladora no mercado de transações que envolve uma determinada atividade (no presente caso o sector da saúde), independentemente de pressões sociais, corporativas ou de outras resultantes de grupos profissionais (BREYER, 1982).

O conceito de regulação baseou-se na experiencia Norte Americana associada ao mercado da energia, transportes e telecomunicações e foi importado pelos países europeus de forma alocada à perspectiva da Nova Gestão Pública (FORTE, 2005). Atualmente, a grande maioria dos países desenvolvidos possui órgãos reguladores em vários mercados emergentes, inclusive no campo da saúde (BUSSE; VAN DER GRINTEN; SVENSSON, 2002). Portugal não foi exceção e criou várias Entidades Reguladoras, entre as quais uma dedicada ao sector da saúde de forma a exercer o direito regulatório e garantir de forma independente a regulação da atividade dos estabelecimentos prestadores de cuidados de saúde (NUNES; REGO, 2010).

Em Portugal, a Entidade Reguladora da Saúde, desde a sua criação em 2003, ganhou enorme relevância pelo fato do sistema de saúde português não ser exclusivamente público, pela existência de múltiplos intervenientes na assistência à saúde e pela crescente falta de intervenção 
do Estado na atividade econômica com extinção do papel do Estado como principal produtor e prestador de serviços públicos à população(MOREIRA; MAÇÃS, 2003).

O presente artigo tem por objetivo descrever, através da análise da legislação publicada e da literatura nacional da especialidade, os pressupostos constitucionais e a caracterização do sistema de saúde português e ainda apresenta todo o enquadramento legal do direito regulatório da saúde em Portugal, que deu origem à criação de uma entidade reguladora independente que atua nas organizações prestadoras de assistência à saúde integradas no sector público, privado ou social.

\section{O DIREITO CONSTITUCIONAL À SAÚDE}

Em Portugal vigora um modelo de Estado social e de direito democrático presente há 43 anos, desde 1976, ano em que foi publicada a primeira versão da Constituição da República Portuguesa (CRP) (DECRETO de 10/04 de 1976) (PORTUGAL, 1976).

A Constituição, em Portugal, reconhece o direito à proteção da saúde para todos os cidadãos através de um Serviço Nacional de Saúde público, universal (para todos os cidadãos residentes) geral (para todos os casos em várias áreas) e de forma gratuita (DECRETO de 10/04 de 1976) (PORTUGAL, 1976).

No cumprimento dos referidos objetivos, a Constituição é clara ao atribuir como principais prioridades: i) o acesso, independentemente da sua condição econômica, nas áreas de promoção da saúde, prevenção da doença (medicina preventiva na atenção primária à saúde), medicina curativa (assistência especializada em hospitais gerais e especializados), na medicina de reabilitação (cuidados de reabilitação pós hospitalares) e na atenção paliativa (fim de vida), integrando assim todo o ciclo de vida, desde o nascimento à morte; ii) a garantia de cobertura nacional na atenção primária, hospitalar e pós hospitalar (criação de uma rede de prestadores); iii) o acesso ao medicamento; iv) a articulação dos serviços públicos de saúde com entidades privadas e sociais; v) o controle da produção, comercialização e o uso dos produtos químicos, biológicos e farmacêuticos e outros meios de tratamento e diagnóstico (artigo $3^{\circ}$ ).

Desde a sua criação, o artigo da Constituição Portuguesa referente ao sector da saúde sofreu várias alterações na sua redação, fruto da evolução ocorrida em Portugal, onde se destacam duas:

A primeira em 1982 aditou um número 4, com a seguinte redação: "O Serviço Nacional de Saúde tem gestão descentralizada e participada". Essa alteração deu origem a entidades periféricas do Ministério da Saúde, constituindo cinco Administrações Regionais de Saúde (ARS) como pessoas coletivas de Direito Público, integradas na Administração Indireta do Estado, dotadas de Personalidade Jurídica, Autonomia Administrativa, Financeira e Patrimonial. Em cada uma das cinco regiões do país, as Administrações Regionais de Saúde, têm por missão garantir à população da respetiva área geográfica de intervenção o acesso às prestações de cuidados de saúde, adequando os recursos disponíveis às necessidades, cumprir e fazer cumprir políticas e programas de saúde na sua 
área de intervenção (LEI CONSTITUCIONAL nº1/1982). (PORTUGAL, 1982). A segunda revisão constitucional em 1989 eliminou o princípio da gratuidade (número 2 do artigo $64^{\circ}$ ), sendo incluída uma tendencial gratuidade (introdução de copagamento, que ficou conhecido com a denominação de " taxa moderadora) e o objetivo de atingir a orientação para "a socialização dos custos dos cuidados médicos e medicamentosos" (alínea c) do número 3 do artigo $64^{\circ}$ da LEI CONSTITUCIONAL nº1/1989). (PORTUGAL, 1989).

A última revisão da Constituição da República Portuguesa data de 2005 (LEI CONSTITUCIONAL n. ${ }^{\circ}$ 1/2005, de 12 de agosto), e tem a seguinte redação:

1. Todos têm direito à proteção da saúde e o dever de a defender e promover.

2. O direito à proteção da saúde é realizado:

a) Através de um serviço nacional de saúde universal e geral e, tendo em conta as condições econômicas e sociais dos cidadãos, tendencialmente gratuito;

b) Pela criação de condições econômicas, sociais, culturais e ambientais que garantam, designadamente, a proteção da infância, da juventude e da velhice, e pela melhoria sistemática das condições de vida e de trabalho, bem como pela promoção da cultura física e desportiva, escolar e popular, e ainda pelo desenvolvimento da educação sanitária do povo e de práticas de vida saudável.

3. Para assegurar o direito à proteção da saúde, incumbe prioritariamente ao Estado:

a) Garantir o acesso de todos os cidadãos, independentemente da sua condição econômica, aos cuidados da medicina preventiva, curativa e de reabilitação;

b) Garantir uma racional e eficiente cobertura de todo o país em recursos humanos e unidades de saúde;

c) Orientar a sua ação para a socialização dos custos dos cuidados médicos e medicamentosos;

d) Disciplinar e fiscalizar as formas empresariais e privadas da medicina, articulando-as com o serviço nacional de saúde, por forma a assegurar, nas instituições de saúde públicas e privadas, adequados padrões de eficiência e de qualidade;

e) Disciplinar e controlar a produção, a distribuição, a comercialização e o uso dos produtos químicos, biológicos e farmacêuticos e outros meios de tratamento e diagnóstico;

f) Estabelecer políticas de prevenção e tratamento da toxicodependência.

4. O serviço nacional de saúde tem gestão descentralizada e participada. (PORTUGAL, 2005).

A inscrição do sector da saúde na Constituição da República Portuguesa, como direito fundamental, não permite que a opção política coloque restrições no acesso à assistência e, pelo contrário, uma das prioridades dos sucessivos Governos, que definem anualmente uma estratégia para a política nacional de saúde sempre com o objetivo de melhorar o acesso e a qualidade dos cuidados prestados. Caso contrário, o Estado estaria cometendo uma inconstitucionalidade por omissão, cujas sanções estão previstas no artigo $283^{\circ}$ da Constituição após análise e avaliação por parte do Tribunal Constitucional (NOVAIS, 2010). 


\section{SISTEMA DE SAÚDE PORTUGUÊS}

Com um Estado de direito fundamental e com a existência do princípio constitucional do direito de proteção da saúde, a prestação pública de cuidados de saúde na atenção primária, hospitalar, pós hospitalar e em cuidados paliativos domina o sistema de saúde português através de um Serviço Nacional de Saúde (SNS) criado em 1979, destinado a todos os cidadãos, independentemente da sua condição social e econômica, e financiado pelo Orçamento Geral do Estado (BARROS, 2013).

O desenvolvimento do SNS (Serviço Nacional de Saúde) foi acompanhado pelo aparecimento e crescimento dos sectores privado e social na prestação de cuidados de saúde, que em regime de complementaridade ao SNS apostaram no mercado ambulatorial em áreas onde a resposta pública era fraca (consultas de especialidade médica e exames de diagnóstico) (CAMPOS, 2008).

Com a publicação da Lei de Bases da Saúde, o Sector privado viu reforçada a sua complementaridade ficando clara a parceria entre os sectores sendo estabelecidos acordos e convenções. Assim, sempre que o sector público de prestação de cuidados não consegue dar resposta imediata aos problemas de saúde de um paciente encaminha o caso para o sector privado e assume a responsabilidade do pagamento por toda a assistência de saúde realizada (BARROS; MACHADO; SIMÕES, 2011).

Por influência da corrente da Nova Gestão Pública em Portugal desde 2002 que se iniciou uma maior tendência para o sector público contratar serviços ao sector privado e, além disso, atribuiu a gestão de quatro hospitais públicos ao sector privado com recurso ao formato jurídico de Parceria Público-Privada (SIMÕES, 2004). Assim, se assistiu gradualmente a uma alteração do papel do Estado que perdeu a sua função de produtor e prestador de serviços (SIMÕES, 2004).

Com o aumento da assistência em saúde por parte de entidades sociais e privadas e perspectivando essa tendência crescente, faltou desde logo a Portugal adaptar-se às novas respostas do modelo de mercado e do modelo de Estado como ocorria já em outros países com a criação de entidades de supervisão e regulação responsáveis por estabelecer mecanismos de monitoramento da atividade que levem em conta todos os fatos, desde a autorização para criar novas unidades de saúde, a vigilância e o licenciamento e ainda a avaliação baseada em critérios de qualidade e de acreditação (GONÇALVES; MARTINS, 2014).

\section{O MODELO REGULATÓRIO NA SAÚDE: DESENVOLVIMENTO E CRIAÇÃO DE UMA ENTIDADE REGULADORA}

O conceito de regulação baseou-se na experiência Norte Americana associada ao mercado da energia, transportes e telecomunicações e foi importado pelos países europeus de forma alocada à perspectiva da Nova Gestão Pública (FORTE, 2005). 
A regulação na saúde tem influência no comportamento e no funcionamento das entidades prestadoras de cuidados de saúde sejam elas públicas ou privadas. Segundo a literatura as atividades de supervisão e monitoramento devem ser realizadas por meio de agências autônomas independentes (agências reguladoras independentes) ou por autoridades administrativas com competência adquirida para o esse efeito (MORAIS; LEAL; BRAZ, 2004).

A grande maioria dos países desenvolvidos possui órgãos reguladores em vários mercados nomeadamente na saúde (BUSSE; VAN DER GRINTEN; SVENSSON, 2002). Portugal é um dos exemplos com a criação de várias Entidades Reguladoras consagradas no $\mathbf{n}^{\mathbf{0}} \mathbf{3}$ do artigo 267. ${ }^{\circ}$ da Constituição, como entidades administrativas independentes entre as quais uma dedicada à saúde a Entidade Reguladora da Saúde que à semelhança do que ocorre com entidades reguladoras de outros setores de atividade (ex. Entidade Reguladora para a Comunicação Social (ERC), Entidade Reguladora dos Serviços Energéticos (ERSE) e Autoridade Nacional de Comunicações (ANACOM)), exerce o direito de regulação e garante de forma independente o regular cumprimento da atividade realizada nos estabelecimentos públicos, privados e sociais que prestam cuidados de saúde (BUSSE; VAN DER GRINTEN; SVENSSON, 2002).

A primeira referência na legislação portuguesa relativa à necessidade de criar uma entidade reguladora para o sector da saúde ocorreu no artigo 37. ${ }^{\circ}$ do regime jurídico das parcerias público privadas na saúde (Decreto-Lei $\mathrm{n}^{\circ}$ 185/2002, de 20 de agosto):

Atividade reguladora - As actividades desenvolvidas no âmbito das parcerias em saúde em regime de gestão e financiamento privados podem ser objecto de regulação económica, sendo o financiamento da entidade reguladora assegurado pelas entidades reguladas, nos termos a definir em diploma próprio (PORTUGAL, 2002).

Outros fatores, segundo a literatura e a análise de documentos legais estiveram na base da opção.

Em Portugal, além da participação acrescida e diversificada de parceiros do setor social e privado na saúde, integrados nas redes de atenção primária, hospitalares e pós hospitalares (cuidados continuados integrados), a influência da Nova Gestão Pública, nos serviços de saúde, gerou um conjunto de fatores que impunham uma imediata regulação do sector, entre os quais se destacam: i) a alteração no papel do Estado (perdeu a sua função de prestador e assumiu mais um papel de regulador); ii) a criação de hospitais públicos geridos com práticas de gestão empresarial; iii) a grande autonomia de gestão, de tipo empresarial, dada aos hospitais num quadro de «mercado administrativo» gerador e potenciador de dinâmicas novas que não podem ser reguladas de forma tradicional; iv) o desenvolvimento de parcerias público-privadas para a gestão dos hospitais públicos (AMADOR, 2012; MARTINS, 2013).

Por conseguinte, era necessário dar uma forte independência à entidade reguladora para separar as funções de forma eficaz e assegurar a independência dos regulamentos, quer em relação ao Estado, quer em relação aos restantes prestadores. Dessa forma, conseguiu-se estabelecer uma 
adequada distância entre a política e o mercado, conferindo à agência reguladora uma autoridade independente que permite criar a estabilidade necessária para a sua função (NUNES, 2014).

Pelo exposto, foi entendimento do Governo, em 2003, nesse momento de profunda reforma estrutural do sector, criar uma entidade reguladora independente, dinâmica e eficaz, a Entidade Reguladora da Saúde (ERS) (NUNES, 2008, 2014). Assim surgiu, com a publicação do Decreto-Lei no 309/2003, de 10 de dezembro a Entidade Reguladora da Saúde (ERS), enquanto entidade pública independente que tem por missão a regulação da atividade dos estabelecimentos prestadores de assistência à saúde, assegurando toda a supervisão e o respetivpo acompanhamento da atividade pública, privada ou realizada pelo setor social (excepto área do medicamento e produtos farmacêuticos), bem como o funcionamento das unidades de saúde, garantindo o adequado acesso aos pacientes com a devida qualidade e garantia de segurança que lhes é devida (PORTUGAL, 2003).

Nos termos do diploma que ditou a sua criação (DECRETO-LEI n ${ }^{\circ}$ 309/2003, de 10 de dezembro), a Entidade Reguladora da Saúde é juridicamente reconhecida como "pessoa coletiva de direito público, dotada de autonomia administrativa e financeira e de património próprio (art. $2^{\circ}{ }^{\circ},{ }^{\circ}{ }^{1}$ ), que tem essencialmente por objeto "a regulação, a supervisão e o acompanhamento, nos termos previstos no presente diploma, da actividade dos estabelecimentos, instituições e serviços prestadores de cuidados de saúde" (art. 3. ${ }^{\circ}$ ). Quanto à sua relação com o Governo, o mesmo diploma é esclarecedor quando refere que a Entidade Reguladora da Saúde "é independente no exercício das suas funções, no quadro da lei, sem prejuízo dos princípios orientadores da política de saúde fixada pelo Governo, nos termos constitucionais e legais, e dos actos sujeitos a tutela ministerial nos termos previstos na lei e no presente diploma." (PORTUGAL, 2003).

A Entidade Reguladora da Saúde, criada pelo Decreto-Lei n. ${ }^{\circ}$ 309/2003, de 10 de dezembro, foi regulamentada com a publicação da Portaria n. ${ }^{\circ} 418 / 2005$, de 14 de abril. Em 2009 pelo Decreto-lei no 127/2009, de 27 de maio resultante da experiência, entretanto decorrida com o funcionamento da ERS foi necessário proceder à revisão do respectivo regime jurídico. Tal revisão impôs-se face à necessidade de adaptar a ERS ao desempenho de funções de regulação da concorrência na saúde e dotá-la dos meios e competências necessárias.

Entre as alterações introduzidas, destaca-se, nomeadamente: i) a criação de um conselho consultivo, fomentando a participação institucionalizada dos sectores interessados; ii) a delimitação mais rigorosa das atribuições e dos poderes da Entidade Reguladora da Saúde, clarificando-os e dando-lhes coerência; iii) a atribuição à Entidade Reguladora da Saúde de funções de regulação económica do sector; iv) a definição mais precisa dos poderes sancionatórios da Entidade Reguladora da Saúde.

Mais tarde, em 2013, a aprovação da Lei-Quadro das Entidades Reguladoras Independentes (LQERI) (LEI n. ${ }^{\circ}$ 67/2013, de 28 de agosto) (PORTUGAL, 2013), obrigou à sua reconformação legislativa. Foi assim necessário adaptar os seus estatutos às exigências decorrentes da lei-quadro das entidades reguladoras, assegurando a manutenção da independência e a eficiência exigíveis a esta entidade, de forma a não comprometer a sua atuação, quer enquanto autoridade reguladora 
independente, quer nas suas funções de coadjuvação ao Governo. (DECRETO-LEI n. ${ }^{\circ}$ 126/2014, de 22 de agosto). Na verdade, a Lei-Quadro das Entidades Reguladoras Independentes veio criar as bases de um regime enformador das várias entidades reguladoras, que foram depois objeto de desenvolvimento em função das especificidades de cada sector.

Assim, no ano 2014, foram alterados os estatutos da ERS, procedendo-se à revogação do Decreto-Lei n. ${ }^{\circ}$ 127/2009, de 27 de maio. A necessidade da nova redação esteve relacionada com o alargamento de competências atribuídas à Entidade Reguladora da Saúde, nomeadamente:

i) Em matéria do licenciamento das unidades de saúde, procedendo ao registo obrigatório e público dos estabelecimentos (art. 26. ${ }^{\circ}$ n..$^{\circ}$ ), o qual que até à data estava sob a esfera de competências das Administrações Regionais de Saúde e,

ii) Ao nível das reclamações, ficando com a responsabilidade de criar um novo sistema transversal a todo o sistema de saúde (artigo $61^{\circ}$ ). Até à data esta matéria era partilhada com a Direção-Geral da Saúde que tratava apenas das reclamações do Serviço Nacional de Saúde. (PORTUGAL, 2014).

A ERS tem atribuído um conjunto de poderes no âmbito da sua atividade (Artigos $17^{\circ}$, $19^{\circ}, 21^{\circ}$ e $22^{\circ}$ do DECRETO-LEI n. ${ }^{\circ} 126 / 2014$, de 22 de agosto):

1. Poderes de regulamentação que incumbem à ERS a possibilidade de emitir regulamentos previstos nos seus estatutos, recomendações e diretivas de caráter genérico, sempre que não se torne necessário a emissão de regulamentos.

2. Poderes de supervisão que obrigam a ERS a zelar pela aplicação das leis e regulamentos e demais normas aplicáveis às atividades sujeitas à sua regulação, no âmbito das suas atribuições; a emitir ordens e instruções, bem como recomendações ou advertências individuais, sempre que tal seja necessário, sobre quaisquer matérias relacionadas com os objetivos da sua atividade reguladora, incluindo a imposição de medidas de conduta e a adoção das providências necessárias à reparação dos direitos e interesses legítimos dos utentes e a efetuar os registos, conceder autorizações e aprovações e emitir, suspender e revogar licenças de funcionamento, nos casos legalmente previstos.

3. Poderes de autoridade e procedimentos de fiscalização que atribuem à ERS o dever de efetuar inspeções e auditorias pontualmente, em execução de planos de inspeções previamente aprovados e sempre que se verifiquem circunstâncias que indiciem perturbações no respetivo setor de atividade, sem prejuízo das competências da Inspeção-Geral das Atividades em Saúde.

4. Poderes sancionatórios relativos a infrações cuja apreciação seja da sua competência, que permitem à ERS desencadear os procedimentos sancionatórios adequados, adotar as necessárias medidas cautelares e aplicar as devidas sanções (PORTUGAL, 2014).

Quanto aos objetivos da regulação em saúde, compete à ERS (DECRETO-LEI n. ${ }^{\circ}$ 
126/2014, de 22 de agosto): i) assegurar o cumprimento dos requisitos do exercício da atividade dos estabelecimentos prestadores de cuidados de saúde, incluindo os respeitantes ao regime de licenciamento dos estabelecimentos prestadores de cuidados de saúde, nos termos da lei; ii) assegurar o cumprimento dos critérios de acesso aos cuidados de saúde, nos termos da Constituição e da lei; iii) garantir os direitos e interesses legítimos dos utentes; iv) zelar pela assistência à saúde com elevada qualidade; v) zelar pela legalidade e transparência das relações econômicas entre todos os agentes envolvidos no sistema de saúde ; vi) promover e defender a concorrência nos segmentos abertos de todo o mercado, em colaboração com a Autoridade da Concorrência (AC) na prossecução de suas atribuições relativas ao sector da saúde. (PORTUGAL, 2014).

No que respeita à garantia de acesso, compete à Entidade Reguladora da Saúde (DECRETO-LEI n. ${ }^{\circ}$ 126/2014, de 22 de agosto):

i) Assegurar o direito de acesso universal e equitativo à prestação de cuidados de saúde nos serviços e estabelecimentos do Serviço Nacional de Saúde (SNS), nos estabelecimentos publicamente financiados, bem como nos estabelecimentos contratados para a prestação de cuidados no âmbito de sistemas ou subsistemas públicos de saúde ou equiparados;

ii) Prevenir e punir as práticas de rejeição e discriminação infundadas de utentes nos serviços e estabelecimentos do SNS, nos estabelecimentos publicamente financiados, bem como nos estabelecimentos contratados para a prestação de cuidados no âmbito de sistemas ou subsistemas públicos de saúde ou equiparados; iii) Prevenir e punir as práticas de indução artificial da procura de cuidados de saúde e

iv) Zelar pelo respeito da liberdade de escolha nos estabelecimentos prestadores de cuidados de saúde, incluindo o direito à informação. (PORTUGAL, 2014).

Em relação à garantia da prestação de cuidados de saúde de qualidade, incumbe à ERS (DECRETO-LEI n. ${ }^{\circ}$ 126/2014, de 22 de agosto): i) Promover um sistema de âmbito nacional de classificação dos estabelecimentos prestadores de cuidados de saúde quanto à sua qualidade global, de acordo com critérios objetivos e verificáveis, incluindo os índices de satisfação dos utentes; ii) Verificar o não cumprimento das obrigações legais e regulamentares relativas à acreditação e certificação dos estabelecimentos; iii) Garantir o direito dos utentes à prestação de cuidados de saúde de qualidade, sem prejuízo das competências da Direção-Geral da Saúde; iv) Propor e homologar códigos de conduta e manuais de boas práticas dos destinatários atividade objeto de regulação pela ERS (PORTUGAL, 2014).

Em relação à aprovação dos novos estatutos da ERS, de acordo com (GONÇALVES; MARTINS, 2014), os novos estatutos (DECRETO-LEI n. ${ }^{\circ}$ 126/2014, de 22 de agosto) proporcionaram uma maior notoriedade para a entidade reguladora que passou assumiu uma importante função. Assim, a importância atribuída à ERS saiu reforçada em 2014 com as competências de: supervisão e fiscalização; resolução de conflitos; desenvolvimento e avaliação e decisão sobre pedidos de licenciamento dos estabelecimentos de saúde; punição de práticas de indução de procura; apreciação de queixas e reclamações; validação dos códigos de conduta e 
manuais de boas práticas e realização de pesquisas de mercado. Contudo, volvidos quatro anos, há referência a algumas limitações, por exemplo nos mecanismos de licenciamento das entidades de saúde que são complexos de acordo com reporte de várias entidades, existindo necessidade de intervir tornando os processos mais fáceis e rápidos.

A Entidade Reguladora da Saúde permaneceu onze anos com os seus estatutos aprovados em 2003 e revistos em 2009. No entanto, no ano 2014 foi entendimento dos legisladores a revisão desse documento legal e, por esse motivo, procederam à revogação do Decreto-Lei $n^{0}$ 127/2009, de 27 de maio. Na base dessa decisão esteve a necessidade de alargar as competências da Entidade Reguladora da Saúde em matéria de licenciamento das unidades de saúde, procedendo ao registo obrigatório e público dos estabelecimentos (art. 26. ${ }^{\circ}$, n. $^{\circ} 2$ ), o qual que até à data estava sob a esfera de competências das Administrações Regionais e ao nível das reclamações ficando com a responsabilidade de criar um novo sistema transversal a todo o sistema de saúde (artigo $61^{\circ}$ ), que até então era uma área partilhada com a Direção-Geral da Saúde. A esse respeito, de acordo com Gonçalves e Martins (2014), os novos estatutos da ERS (Decreto-Lei n. ${ }^{\circ}$ 126/2014, de 22 de agosto) proporcionaram uma maior notoriedade para a entidade reguladora que passou assumiu uma importante função. Assim, a importância atribuída à ERS saiu reforçada em 2014 com as competências de: i) monitoramento e fiscalização; ii) resolução de conflitos; iii) desenvolvimento e avaliação e decisão sobre pedidos de licenciamento dos estabelecimentos de saúde; iv) punição de práticas de indução de procura; v) apreciação de queixas e reclamações; vi) validação dos códigos de conduta e manuais de boas práticas; vii) realização de pesquisas de mercado (PORTUGAL, 2014).

\section{CONCLUSÃO}

Em Portugal existe um sistema de saúde predominantemente público administrado por um Serviço Nacional de Saúde previsto na Constituição da República e que garante uma proteção a todos os cidadãos nas mais variadas prestações de saúde. Porém, a participação privada e social no sistema de saúde tem se demonstrado muito importante num regime de complementaridade.

Com o desenvolvimento do sector privado e a influência da Nova gestão pública (adoção da gestão empresarial dos hospitais públicos e estabelecimento de parcerias público privadas) levou o Estado agora empresário a agir de forma mais intervencionista sobre os agentes econômicos. Por esse motivo, em 2003, foi reconhecida a importância de promover a regulação no sector da saúde e tomada a decisão de criar uma entidade reguladora que entre outras funções permitiria um maior monitoramento, a definição, avaliação e decisão com critérios comuns para licenciamento e avaliação de unidades de saúde em todos os sectores: público, privado e social.

A importância da ERS foi reforçada em 2014 com a publicação dos seus novos estatutos que vieram reforçar as suas competências, deixando a entidade preparada para um futuro quadro regulamentar com competências reforçadas no âmbito do monitoramento das atividades em saúde e no cumprimento das disposições legais adequadas a um funcionamento adequado às necessidades 
dos pacientes, respeitando as normas de qualidade e garantindo as melhores condições de segurança.

Em conclusão, a ampla abrangência da atividade regulatória exercida pela ERS revela a ação do direito regulatório no sector da saúde e reconhece definitivamente a importância da articulação e da complementaridade entre os sectores público, privado e social no quadro geral de assistência à saúde. Em relação às limitações jurídicas falta ainda melhorar os mecanismos de licenciamento das entidades de saúde, tornando o processo mais fácil e rápido.

\section{REFERÊNCIAS}

AMADOR, Olívio Mota. Desafios da regulação da saúde em Portugal nos tempos de crise. Revista da Concorrência e Regulação, Coimbra, PT, v. 10, p. 140-144, 2012.

BARROS, Pedro Pita. Economia da saúde. Coimbra: Almedina, 2013.

BARROS, Pedro Pita; MACHADO, Sara; SIMÕES, Jorge. Health systems in transition: Portugal health system review. Portugal: European Observatory on Health Systems and Policies, 2011.

BREYER, Stephen. Regulation and its reform. Cambridge: Harvard University Press, 1982.

BUSSE, Richard; VAN DER GRINTEN, Tom; SVENSSON, Per-Gunnar. Regulating entrepreneurial behaviour in hospitals: theory and practice (126-145). Buckingham: European Observatory on Health Care Systems Series, 2002.

CAMPOS, António. Reformas no setor da saúde- o fio condutor. Coimbra: Almedina, 2008.

FERNANDES, Adalberto Campos. Combinação público-privado em saúde: impacto no desempenho no sistema e nos resultados em saúde no contexto português. Lisboa: Instituto Superior de Ciências Sociais e Política, 2015.

FORTE, André Matos. Entidade reguladora da saúde: o Decreto-Lei n. ${ }^{\circ}$ 309/2003, de 10 de dezembro. Coimbra: Faculdade de Direito, Universidade de Coimbra, 2005.

GONÇALVES, Pedro; MARTINS, Licínio. O novo regime das entidades independentes de regulação. Lisboa: Entidade Reguladora da Saúde, 2014.

MARTINS, Licínio Lopes. Direito administrativo da saúde. Tratado de direito administrativo. Coimbra: Almedina, 2013.

MORAIS, Luís Miguel; LEAL, Maria; BRAZ, Paula. Entidade reguladora da saúde, que futuro? Lisboa: Observatório Português dos Sistemas de Saúde, 2004.

MOREIRA, Vital; MAÇÃS, Fernanda. Autoridades reguladoras independentes, estudo e projeto da lei-quadro. Coimbra: Editora Coimbra, 2003.

NOLL, Roger. Focusing organisational research on regulation. Berkeley: University of California Press, 1985.

NOVAIS, Jorge. Constituição e Serviço Nacional de Saúde. Revista de Direitos Fundamentais 
\& Justiça, Belo Horizonte, MG, v. 11, p. 85-109, 2010.

NUNES, Rui. A regulação independente na saúde. Coimbra: Almedina, 2008.

NUNES, Rui. Regulação da Saúde. Porto, Portugal: Vida Económica, 2014.

NUNES, Rui; REGO, Guilhermina. Gestão da saúde. Lisboa: Prata e Rodrigues, 2010.

PORTUGAL. Constituição da República Portuguesa (primeira revisão). Lei Constitucional n. ${ }^{\circ}$ 1/1982. Diário da República, [Lisboa, PT], n. ${ }^{\circ}$ 227, 30 set. 1982. Série I.

PORTUGAL. Constituição da República Portuguesa. Decreto 10/04 de 1976. Aprova a Constituição da República Portuguesa. Diário da República, [Lisboa, PT], n. ${ }^{\circ}$ 86, 10 abr. 1976. Série I.

PORTUGAL. Constituição da República Portuguesa. Lei Constitucional n. ${ }^{\circ} 1 / 1989$. Diário da República, [Lisboa, PT], n. ${ }^{\circ} 155,08$ jul. 1989. Série I.

PORTUGAL. Decreto-Lei n. ${ }^{\circ}$ 126/2014. Diário da República, [Lisboa, PT], n. ${ }^{\circ}$ 161, 22 ago. 2014. Série I-A.

PORTUGAL. Decreto-Lei nº 309/2003. Diário da República, [Lisboa, PT], n. o 284, 12 out. 2003. Série I-A.

PORTUGAL. Lei $n^{\circ}$ 1/22005. Sétima revisão constitucional. Diário da República, [Lisboa, PT], n. ${ }^{\circ} 155,12$ ago. 2005 . Série I-A.

PORTUGAL. Lei no 48/90. Lei de Bases da Saúde. Diário da República, [Lisboa, PT], n. ${ }^{\circ}$ 195, 24 ago. 1990. Série I.

PORTUGAL. Lei nº7/2013. Diário da República, [Lisboa, PT], n. ${ }^{\circ} 165,28$ ago. 2013. Série I.

SIMÕES, Jorge. As parcerias público-privadas no sector da saúde em Portugal. Revista

Portuguesa de Saúde Pública, Lisboa, PT, v. 4, p. 79-90, 2004.

Como citar: NUNES, Alexandre Morais; RAPOSEIRO, Rosa. Saúde em Portugal: Análise do direito regulatório. Revista do Direito Público, Londrina, v. 16, n. 1, p. 85-96, abr. 2021. DOI: 10.5433/24157-108104-1.2021v16n1p. 85. ISSN: 1980-511X

Recebido em: 28/03/2019

Aprovado em: 16/07/2019 